\title{
The Library's Contribution to Student Learning: Inspirations and Aspirations
}

\section{Megan Oakleaf}

George Kuh and Robert Gonyea's 2003 article entitled “The Role of the Academic Library in Promoting Student Engagement in Learning" appeared in College and Research Libraries in July 2003, after being presented as an invited paper at the ACRL 11th National Conference that April. ${ }^{1}$ Their paper presentation stands out in my mind to this day. It was my first time both attending and presenting at an ACRL conference, and I was nervous. My co-presenter (Amy VanScoy) was my supervisor, and our library director (Susan Nutter) sat in the front row. The stakes were high! Luckily for me, two things happened that day. First, our presentation was not a disaster. Second, Kuh and Gonyea's session immediately followed ours. With my presentation duties discharged, I was able to finally relax and fully engage with the content they shared. As it turns out, it was a good time to pay attention. Over the last several years, my research and interests have dovetailed with the message they communicated in their presentation, and George has been particularly helpful to me in my efforts to capture and convey the value and impact of academic libraries.

It's important to point out that Kuh and Gonyea aren't librarians; they're assessment experts, prolific authors, and national leaders in conversations about college experience, student success, and institutional quality. At the time of this article's publication, they were affiliated with the College Student Experiences Questionnaire (CSEQ), the survey that served as the research content for their article. Despite not being librarians, or perhaps because they aren't librarians, Kuh and Gonyea offer a unique, valuable, and insightful contribution to literature of librarianship. It's a rare treat to see oneself from another perspective, particularly when the perspective is well conceived, intentioned, researched, and written. We can all use a little help from our friends in the academy, and Kuh and Gonyea strike exactly the right tone. They don't pretend to be librarians, and they don't shout from on high or apologize for any lack of librarianesque perspective. They share what they've learned from their research as teammates and partners in the pursuit of success for all students. This is part of what makes their contribution to College and Research Libraries so special and why their article was so well received in 2003 as well as relevant to our profession today, more than a decade later.

Throughout their article, Kuh and Gonyea's treatment of academic libraries is considerate and complimentary. They are careful to state that "the library is the physical manifestation of the core values and activities of academic life" (359), and that "the library's central role in the academic community is unquestioned" (359). They write that "it is almost heretical to ask...but just what does the library contribute to student learning?" (359). Today, the library's place in the academy is often questioned, and dem-

Megan Oakleaf is an Associate Professor in the iSchool at Syracuse University; e-mail: moakleaf@syr.edu. (C) 2015 Megan Oakleaf, Attribution-NonCommercial (http://creativecommons.org/licenses/by-nc/3.0/) CC BY-NC. 
onstrating what the library contributes to learning is a key issue facing the profession. However, Kuh and Gonyea were writing at a time when "the shift from emphasizing teaching to focusing on student learning as the primary goal of undergraduate education is gaining traction in all types of postsecondary institutions" (360), an emphasis that is now firmly entrenched in our institutions and our thinking. They note that "the implications [of this shift] for the library are plain: students' experiences with academic libraries should make direct or indirect contributions to desired outcomes of college" (360). They summarize early evidence related to the issue of library impact by authors including Powell, ${ }^{2}$ Glendale Community College, ${ }^{3}$ Ory and Braskamp, ${ }^{4}$ Terenzini, ${ }^{5}$ and Whitmire ${ }^{6}$ before going on to state their main research question: "To what extent do libraries today contribute to information literacy and other aspects of student learning?" (361).

To answer their research question, Kuh and Gonyea mined the CSEQ for evidence that the library makes an impact on student learning. The CSEQ was a student selfreport survey that sought to "assess the quality of effort students devote to educationally purposeful activities... [as] quality of effort is the single best predictor of what students gain from college" (362). [The CSEQ ceased operation in early 2014; many of the questions were folded into the National Survey of Student Engagement (NSSE). More information on the NSSE is available at http://nsse.iub.edu/.] Their analysis turned up some noteworthy results. For example, they found that "students of color use the library more frequently compared with white students; students majoring in the humanities and preprofessional fields use the library more often than those majoring in business, math, or science" (368). They discovered that "students who do not have a computer where they live or work (or nearby) tend to use the library more" and that "students at doctoral/research-extensive universities use the library less frequently compared with students attending the other four types of institutions" (368). They also determined that academic challenges, including course learning experiences that require "put[ting] together different facts and ideas, work[ing] on projects integrating ideas from various sources, and appl[ying] class materials to other areas in life," and student-faculty interactions that result in "work[ing] harder than you thought you could to meet faculty expectations and work[ing] harder due to instructor feedback" relate positively to library use (368). In terms of information literacy learning, they learned that "students who perceive that their institution places a strong emphasis on acquiring information literacy skills report higher gains in information literacy" (369).

While these results are interesting and potentially quite useful, Kuh and Gonyea's answer to their central research question was "disappointing" (371). Ultimately, they found that "none of the individual library activities [included in the CSEQ] appear to have a substantial influence on any of the three outcome variables [including gains in information literacy learning, overall gains in college, and satisfaction], after controlling for student and institutional characteristics, perceptions of the environment, and academic challenge" (369). They provide three possible explanations for the lack of connection between library activities and information literacy learning: 1) that the CSEQ may not be a valid surrogate for information literacy learning; 2) that a lack of baseline measures for information literacy learning makes student self-reported estimates of learning problematic; and 3) that information literacy learning is not an outcome of library activities alone, but rather a result of multiple and cumulative experiences over time (371). They clearly state that they found "no silver bullet (or single intervention) that will produce an information literate college graduate" (371), but they are undaunted by that finding since "rarely does any single experience or set of activities during college affect student learning and personal development one way or another; rather, what is most important to college impact is the nature and breadth 
of a student's experiences over an extended period" (373). Of course, for librarians, the allure of a simple answer to the question of the library's impact on student learning and other positive outcomes is strong. While a straightforward answer is not revealed by Kuh and Gonyea's research, the complexity of their findings have provided librarians with a rich area for productive follow-on research.

To this end, Kuh and Gonyea make a number of substantive recommendations for librarians. For example, they suggest that students appear to make information literacy learning gains when their campus emphasizes information literacy as an important learning area, and encourage librarians to collaborate campuswide to prioritize and communicate the importance of information literacy (371). They also point out that "higher education needs more investigations into the library's effectiveness in promoting student learning" and suggest determining "the kinds of student interactions with librarians beyond those represented on the CSEQ that effectively promote learning" as well as ascertaining "which approaches are most effective in teaching information literacy" (372). Finally, they recommend investigating what library interactions are associated with retention and graduation (372).

In many ways, Kuh and Gonyea's article reflects the time period in which it was published. It underscores the shifting climate of higher education from a teachingfocused to student-centric emphasis, trumpets the ever-growing call for accountability and demonstration of value, and seeks to use the evidence in hand to answer the question, "To what degree does what we're doing make a difference?" Like much of the early work in this area, the authors find it difficult to connect library activities to discernable impacts for students. As they acknowledge, this problem stems in part from the nature of the research materials (student self-report surveys) and the lack of other rigorous assessments of student learning, particularly in the area of information literacy. The problem also is rooted in the difficulty of the goal, namely, to isolate the impact of the library apart from other student learning experiences.

While Kuh and Gonyea's article is an exemplar of early research exploring the impact of libraries on learning and other positive student outcomes, it also foreshadowed the research efforts librarians have undertaken in the years since its publication. In the intervening years, librarians have addressed many of the problems that caused difficulty for the authors. For example, Kuh and Gonyea point out two challenges for their study: first, using the CSEQ as a proxy for information literacy learning and second, the lack of other information literacy learning measures. Since 2003, librarians have expanded their options for assessing information literacy learning, expanding self-report survey approaches including Project Information Literacy and the new library add-on module for NSSE, developing tests such as SAILS and iSkills, and creating performance assessments and corresponding rubrics. They've investigated the strengths and weaknesses of each approach and often attempt to triangulate their assessments when high-stakes decisions will be made based on the results. ${ }^{7}$

Librarians have also responded to Kuh and Gonyea's research finding that students appear to make greater gains in information literacy learning when their campuses emphasize that as an important learning goal. Librarians have long strived to communicate, educate, and collaborate with students and faculty on the role of information literacy in campuswide learning, and their efforts have expanded in the years since this study was presented. Many librarians have successfully implemented information literacy into general education requirements, reported information literacy data to accreditors, developed curriculum-integrated information literacy instruction, and achieved other accomplishments to this end. Much of this information literacy integration, collaboration, and communication were made possible by the ACRL Information Literacy Competency Standards for Higher Education (http://www.ala. 
org/acrl/standards/informationliteracycompetency), a document that, at the time of this writing, ACRL seems likely to "sunset." ACRL is now encouraging librarians to use the new Framework for Information Literacy for Higher Education (http://acrl.ala. org/ilstandards/) as inspiration for developing their local definitions and outcomes for information literacy instruction. The Framework represents a shift in ACRL's conception of information literacy, and the transition will likely impact librarians' campuswide information literacy initiatives as well as requiring retooling of some assessment approaches. Even so, librarians remain dedicated to ensuring that their campuses emphasize and assess information literacy as an important learning goal, at least in part due to Kuh and Gonyea's findings.

Other recommendations mentioned by Kuh and Gonyea are the subject of current research projects. The most important among these is the suggestion that librarians need to investigate and determine what library activities and interactions impact student learning (information literacy and otherwise) and other outcomes such as retention and graduation. In the last five years, exploration of these topics has exploded. In 2010, ACRL published The Value of Academic Libraries: A Comprehensive Review and Report in an effort to collect and share what was known about academic library impact and thus provide a starting point for new research in the area. ${ }^{8}$ Of course, Kuh and Gonyea's article was included in the report, and Kuh also served on the Advisory Committee overseeing the development of the report. Since then, numerous studies seeking to explore the impact of libraries and librarians on student learning and other important outcomes have been published and presented, including work at the University of Huddersfield, ${ }^{8}$ the University of Wollongong, ${ }^{10}$ the University of Minnesota, ${ }^{11}$ as well as smaller studies presented at the Library Assessment Conference and elsewhere. ${ }^{12} \mathrm{In}$ addition to the studies that have been shared thus far in the library community, other research, conducted by individual libraries and librarians and supported by ACRL and other professional associations through programs like Assessment in Action (http:// www.ala.org/acrl/AiA), are in progress and may be shared with the library community at the upcoming ACRL National Conference in Portland.

Another issue Kuh and Gonyea raised as a difficulty in their study is still challenging the library profession today. In their explanation of why no library activities appear to impact the outcome variables explored in their study, Kuh and Gonyea point out that student learning is not likely the result of library activities only, but instead the results of multiple experiences over time. Indeed, Kuh and Gonyea do not appear to expect that any one activity or interaction could possibly be linked to significant learning gains or other desirable outcomes, a position no doubt based on their extensive knowledge of higher education research which repeatedly demonstrates that most outcomes are a result of many and variable student experiences, activities, and interactions. Despite their example, librarians often seem to pursue the goals of demonstrating that substantial learning results from one-time, isolated interactions with librarians or linking other outcomes (such as retention or graduation, student success, achievement, or career advancement) definitively to the library and the library alone. Falling short of this lofty goal, authors or presenters in library venues often use apologetic tones when they acknowledge that they have found correlations between library interactions and learning or other outcomes, but no causal links between them. In fact, no apologies are required. Indeed, many scholars believe, particularly in social science research fields, not only that correlation does not imply causation, but also that demonstration of causation is impossible, because there are too many unknown and uncontrollable factors. The problem of unknown and uncontrollable factors is especially significant in educational settings, where students are potentially influenced by endless prior and concurrent experiences that impact research results; 
and randomized control studies, usually considered the gold standard of experiment research, are not typically feasible. Other scholars acknowledge that definitive causation may not be provable, but believe that-given consistently strong correlations, a theoretical model that supports a causative connection, and research that controls for all other factors and alternative explanations - it may be reasonable to argue that a causative relationship exists and to act on that assumption. If a librarian subscribes to the first idea (that causation is not demonstrable), then strong, positive correlations are a suitable end goal for research and the results of such research can be communicated and employed to make decisions and take actions. If a librarian is persuaded by the second position (that correlations bolstered by proven theory and shown to be free of all other influencing factors are equivalent to causation), then strong, positive correlations must be contextualized within a larger theory and additional factors and explanations must be ruled out before the results of such research can be declared causative and then shared and used to make decisions and take actions. (Note: In the second scenario, librarians should also be prepared to explain their claims of causality to those who subscribe to the first idea of causation.)

Arguments about causation aside, strong, positive correlations are the stuff of action for librarians. When librarians determine that particular library activities or interactions are correlated with positive learning or other outcomes, those correlations point the way for librarians to plan improvements to library services and resources. If students who exhibit a particular library interaction behavior or set of behaviors are more likely to demonstrate learning gains or other positive outcomes, then it seems reasonable for librarians: 1) to instruct and encourage students to adopt these behaviors; 2) to ensure that the library services, resources, and systems that students encounter as they engage in these library interaction behaviors are streamlined, effective, efficient, and rewarding; 3) to communicate the success of students who engage in these behaviors to stakeholders including but not limited to faculty, administrators, parents, and the students themselves; and 4) to engage additional research to learn more about the interconnectedness between these behaviors and positive student outcomes.

In pursuit of the fourth goal above, librarians can look forward to increasing information about student library activities and interactions. While current research correlating library activities and interactions with learning and other positive student outcomes is exciting, the future - one with ever-increasing amounts of learning analytics data - is even more so. Currently, librarians seeking to answer Kuh and Gonyea's question, "What do libraries and librarians contribute to student learning and other positive outcomes?" have been challenged by a host of information challenges including limited availability of library data (because the data are not collected, not maintained, or not accessible due to technological issues or librarian skill gaps), lack of integration between library information systems and campus student information systems, inaccessible vendor data, and issues related to privacy and data security. These challenges and unforeseen others may not be quickly or easily surmountable. At the same time, the trend in higher education is moving inexorably toward the collection of greater amounts of information, particularly in the service of improving and increasing positive student outcomes. Certainly, librarians have myriad models to learn from within the academy, both in the academic arena and in the student affairs sector. Due at least in part to accreditation requirements, other campus units have engaged in rigorous assessment research for years, and librarians would do well to seek out, develop, and maintain collaborations with campus partners including academic faculty, student support staff, institutional researchers, and educational assessment professionals. It's reasonable to expect that, as librarians gain access to more complex and more revealing information about student library activity and interactions as well as campus 
level learning analytics, they will gain the connections, skill, confidence, interest, and ability to conduct more sophisticated analyses of the ways in which libraries make a difference in students' lives.

Clearly, Kuh and Gonyea provide both an early example of a burgeoning research field and an exemplar for present and future authors to emulate. They engage important issues facing all of higher education, deliver actionable research results based on expansive data collection and rigorous methodology, and bridge the artificial but influential divisions of higher education to do it. As their reward, they gained our attention and respect; their article is one of the top five downloaded articles at the College and Research Libraries site a decade after its publication. In the intervening years, we've all been rewarded with the substantial research that has followed their lead, and I look forward to the future publications that will add to their legacy.

\section{Notes}

1. George D. Kuh and Robert M. Gonyea, "The Role of the Academic Library in Promoting Student Engagement in Learning" College and Research Libraries 64, no. 4 (2003): 256-282.

2. R.R. Powell, "Impact Assessment of University Libraries," Library and Information Science Research 14 (1992). (2001).

3. Glendale Community College, "Information Literacy Competency Improves Grades"

4. J.C. Ory and L.A. Braskamp, "Involvement and Growth of Students in Three Academic Programs," Research in Higher Education 28 (1998).

5. P.T. Terenzini, "Influences Affecting the Development of Students' Critical Thinking Skills," Research in Higher Education 36, no. 1 (1995); P.T. Terenzini et al., "First-Generation College Students: Characteristics, Experiences and Cognitive Development," Research in Higher Education 37, no. 1 (1996).

6. E. Whitmire, "Development of Critical Thinking Skills: An Analysis of Academic Library Experiences and Other Measures," College and University Research Libraries 59, no. 3 (1998).

7. M.J. Oakleaf, "Dangers and Opportunities: A Conceptual Map of Information Literacy Assessment Tools," portal: Libraries and the Academy 8, no. 3 (2008).

8. Association of College and Research Libraries, The Value of Academic Libraries: A Comprehensive Research Review and Report, researched by Megan Oakleaf (Chicago: ACRL, 2010).

9. G. Stone and B. Ramsden, "Library Impact Data Project: Looking for the Link between Library Usage and Student Attainment," College \& Research Libraries 746 (2013).

10. B. Cox and M. Jantti, "Discovering the Impact of Library Use and Student Performance," EDUCAUSE Review 474 (2012).

11. K. Soria, J. Fransen, and S. Nackerud, "Library Use and Undergraduate Student Outcomes: New Evidence for Students' Retention and Academic Success," portal: Libraries and the Academy 132 (2013).

12. M.J. Oakleaf, "Correlating Library Services, Expertise, and Resources with Student Learning," Information Outlook 18, no. 2 (2014). 